\title{
Carcinoid tumor of the minor papilla in complete pancreas divisum presenting as recurrent abdominal pain
}

\author{
Yong Gil Kim, Tae Nyeun Kim*, Kyeong Ok Kim
}

\begin{abstract}
Background: Tumors of the minor papilla of the duodenum are extremely rare, and they are mostly neuroendocrine tumors, such as somatostatinomas and carcinoid tumors. However, true incidence of carcinoid tumors in minor papilla might be much higher, because patients with minor papillary tumors usually remain asymptomatic. We report a very unusual case of carcinoid tumor in a patient with complete pancreas divisum with a review of the literature.

Case presentation: A 56-year-old female patient was referred for evaluation of pancreatic duct dilatation noted on abdominal ultrasonography and computerized tomography. She complained of intermittent epigastric pain for 6 months. A MRCP and ERCP revealed complete pancreas divisum with dilatation of the main pancreatic duct. On duodenoscopy, a small, yellows, subepithelial nodule was visualized at the minor papilla; biopsy of this lesion revealed a carcinoid tumor. She underwent a pylorus-preserving pancreaticoduodenectomy. The histologic evaluation showed a single nodule, $1 \mathrm{~cm}$ in diameter, in the submucosa with duodenal and vascular invasion and metastasis to the regional lymph nodes.

Conclusion: Although the size of the carcinoid tumor was small and the tumor was hormonally inactive, the concomitant pancreas divisum led to an early diagnosis, the tumor had aggressive behavior. Carcinoid tumors of the minor papilla should be included in the differential diagnosis of recurrent abdominal pain or pancreatitis of unknown cause.
\end{abstract}

\section{Background}

Tumors of the minor papilla of the duodenum are very rare; the majority of tumors of the minor papilla of the duodenum are neuroendocrine tumors (NETs), such as somatostatinomas and carcinoid tumors [1-7]. Carcinoid tumors arise from enterochromaffin cells, and gastrointestinal carcinoids are usually located in the appendix, ileum, stomach, and rectum. Carcinoids of the minor papilla are extremely rare; only 8 cases have been reported in the literature [1-8].

Pancreas divisum is the most common congenital anomaly of the pancreas, resulting from failure of fusion between the dorsal and ventral pancreatic ducts. Most exocrine secretions of the pancreas drain through the dorsal pancreatic duct and the minor papilla in the

\footnotetext{
* Correspondence: tnkim@ynu.ac.kr

* Correspondence: tnkim@ynu.ac.kr
Department of Internal Medicine, Yeungnam University College of Medicine, Daegu, South Korea
}

pancreas divisum. Patients with pancreas divisum usually have no clinical symptoms, but sometimes have recurrent abdominal pain or pancreatitis when disturbances in drainage of pancreatic secretion through the minor papilla occur.

We report a very unusual case of a carcinoid tumor of the minor papilla arising in a patient with complete pancreas divisum who presented with recurrent abdominal pain.

\section{Case persentation}

A 56-year-old female was referred to our department for evaluation of dilatation of the main pancreatic duct noted on abdominal ultrasonography and CT scan. She complained of intermittent epigastric pain 6 months prior to the referral. She did not drink alcohol or take any medications, and had no significant medical history. She denied sweating, diarrhea, or facial flushing. 
Laboratory data on admission were as follows: total bilirubin, $0.47 \mathrm{mg} / \mathrm{dL}$; AST, $41 \mathrm{U} / \mathrm{L}$; ALT, $33 \mathrm{U} / \mathrm{L}$; ALP, $161 \mathrm{U} / \mathrm{L} ; \mathrm{GGT}, 32 \mathrm{U} / \mathrm{L}$; and amylase, $147 \mathrm{U} / \mathrm{L}$. The complete blood count, urine analysis, and serum electrolytes were within normal limits. The CA 19-9 was 7.99 $\mathrm{U} / \mathrm{ml}$ and the 5-HIAA was $21.44 \mathrm{mg} /$ day.

On the CT scan, the pancreatic duct was diffusely dilated without a definite mass and the common bile duct was slightly dilated (Figure 1). Magnetic resonance cholagiopancreatography (MRCP) showed a dilated dorsal pancreatic duct crossing over the common bile duct with stenosis at the minor papailla. The ventral duct appeared to be normal and there was no communication between the dorsal and ventral ducts, indicating pancreas divisum (Figure 2). The common bile duct was slightly dilated, and narrowing of the distal common bile duct (CBD) was noted without passage disturbance. A duodenoscopic examination revealed a $1 \mathrm{~cm}$ yellow, bulging, nodular lesion with an intact mucosal surface in the minor papilla. The orifice of the minor papilla was not visible due to the nodule and cannulation was not possible (Figure 3A). On endoscopic retrograde cholangiopancreatography (ERCP), the major papilla appeared to be normal. Injection of contrast through the major papilla revealed a short and slender ventral duct confined to the pancreas head with no visualization of ducts in the body and tail. The ventral duct gradually diminished in caliber and was arborizing (Figure 3B). Endoscopic ultrasonography (EUS) showed a $1.3 \mathrm{~cm}$ illdefined hypoechoic mass in the submucosal layer of the minor papilla (Figure 4). Multiple deep biopsies of this nodule revealed a carcinoid tumor.

Under the diagnosis of a carcinoid tumor of the minor papilla in complete pancreas divisum, the patient underwent a pylorus-preserving pancreaticoduodenectomy. The resected specimen consisted of duodenum, pancreas, and CBD. There was a $1.2 \times 1.0 \mathrm{~cm}$ submucosal lesion of the minor papilla (Figure 5).

On the microscopic examination, uniform and roundshaped cells were visualized in or around the heterotopic pancreas in the minor papilla, arranged in a solid nest or tubular pattern, suggesting a carcinoid tumor.

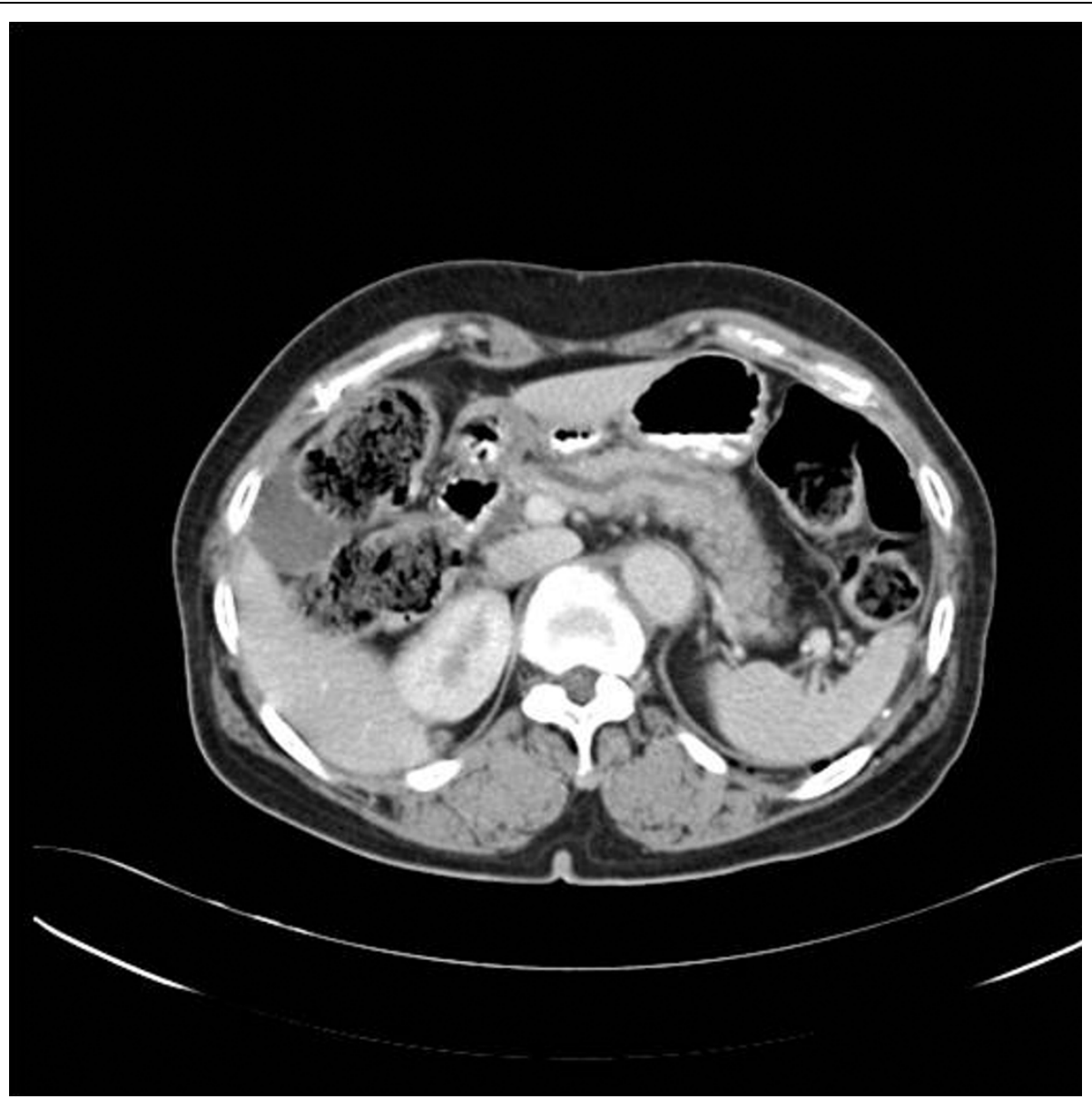

Figure 1 Abdominal CT finding. The pancreatic duct was diffusely dilated without a definite obstructive mass lesion. 


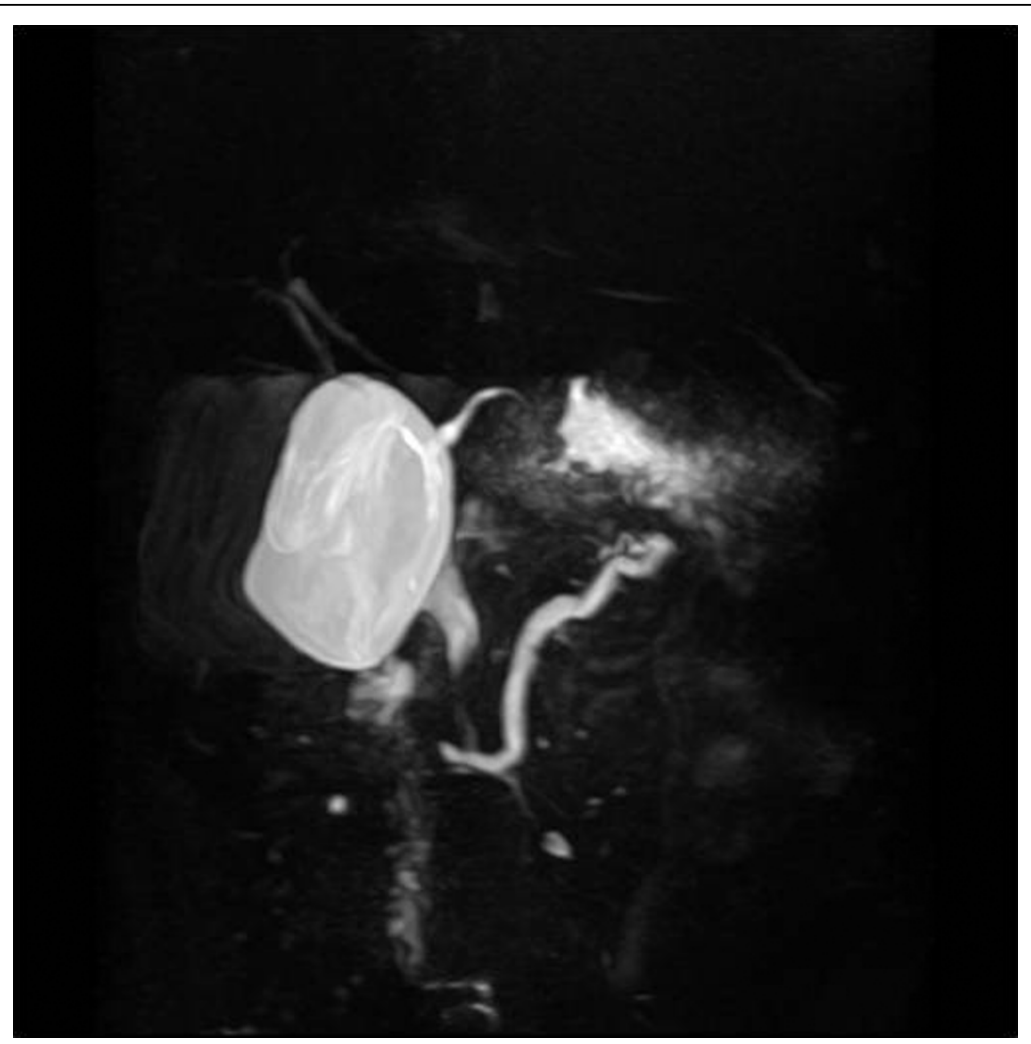

Figure 2 Magnetic resonance cholangiopancreatographic finding. The dorsal pancreatic duct was slightly enlarged with stenosis at the minor papilla. Furthermore, it crossed over the common bile duct. The ventral duct appeared to be normal and there was no communication between the dorsal and ventral ducts, indicating pancreas divisum.
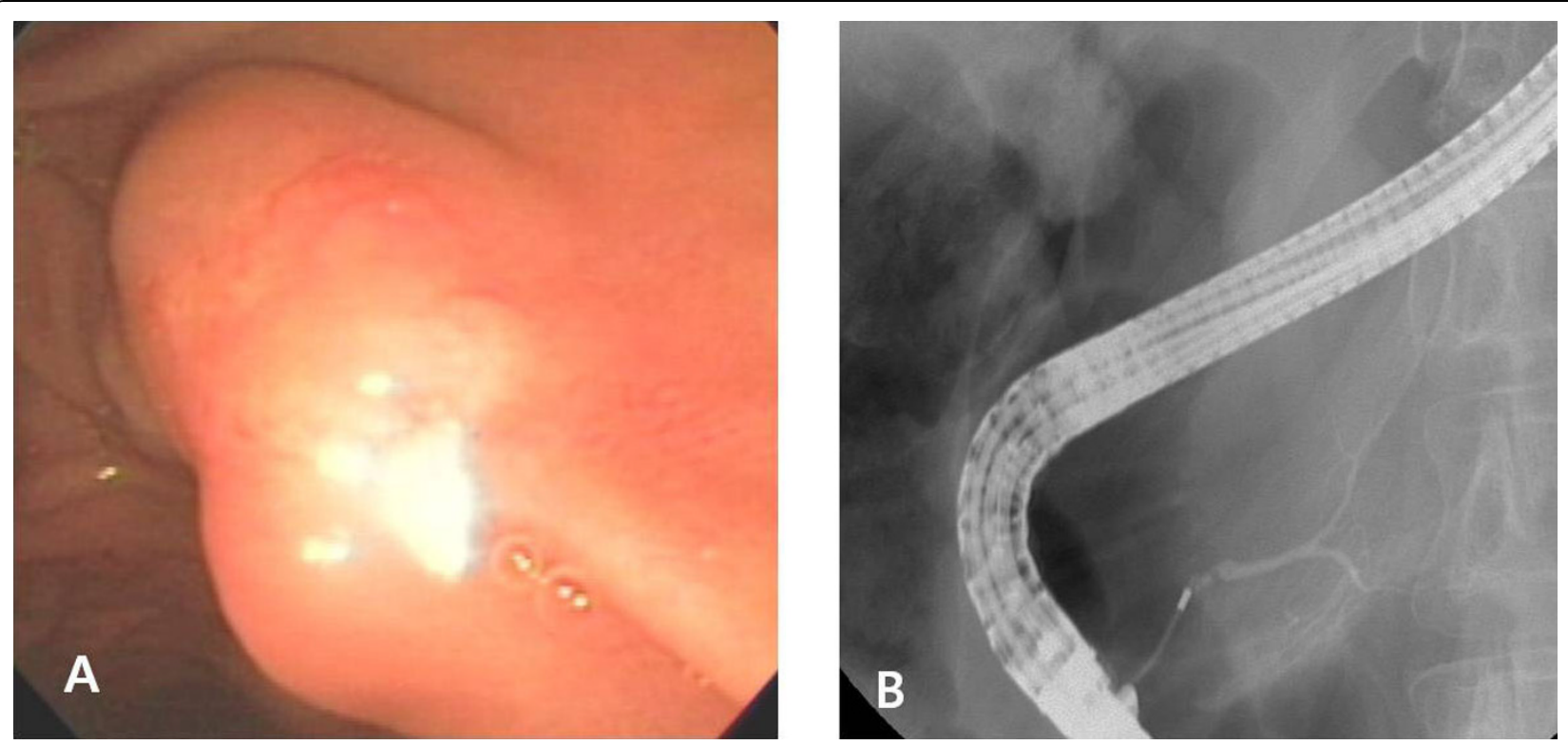

Figure 3 ERCP finding. A, Duodenoscopic examination revealed $1 \mathrm{~cm}$ sized yellowish bulging nodular lesion with intact mucosal surface at minor papilla. B, Injection of contrast through major papilla revealed short and slender ventral duct confined to pancreas head with no visualization of ducts in body and tail. The ventral duct was gradually diminishing in caliber and arborizing. 


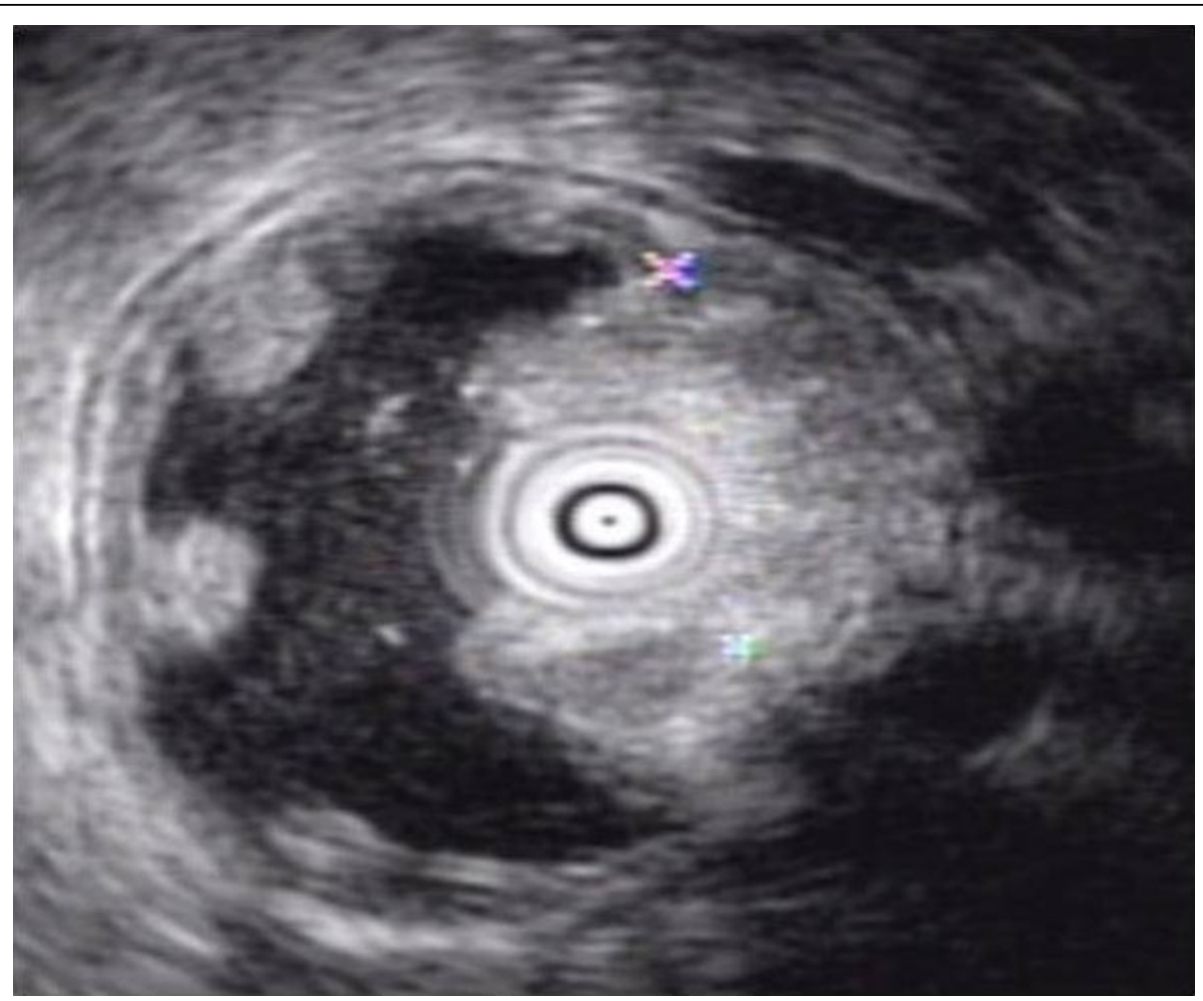

Figure 4 Endoscopic ultrasonography finding. There was $1.3 \mathrm{~cm}$ sized ill defined hypoechoic mass in submucosal layer at minor papilla.
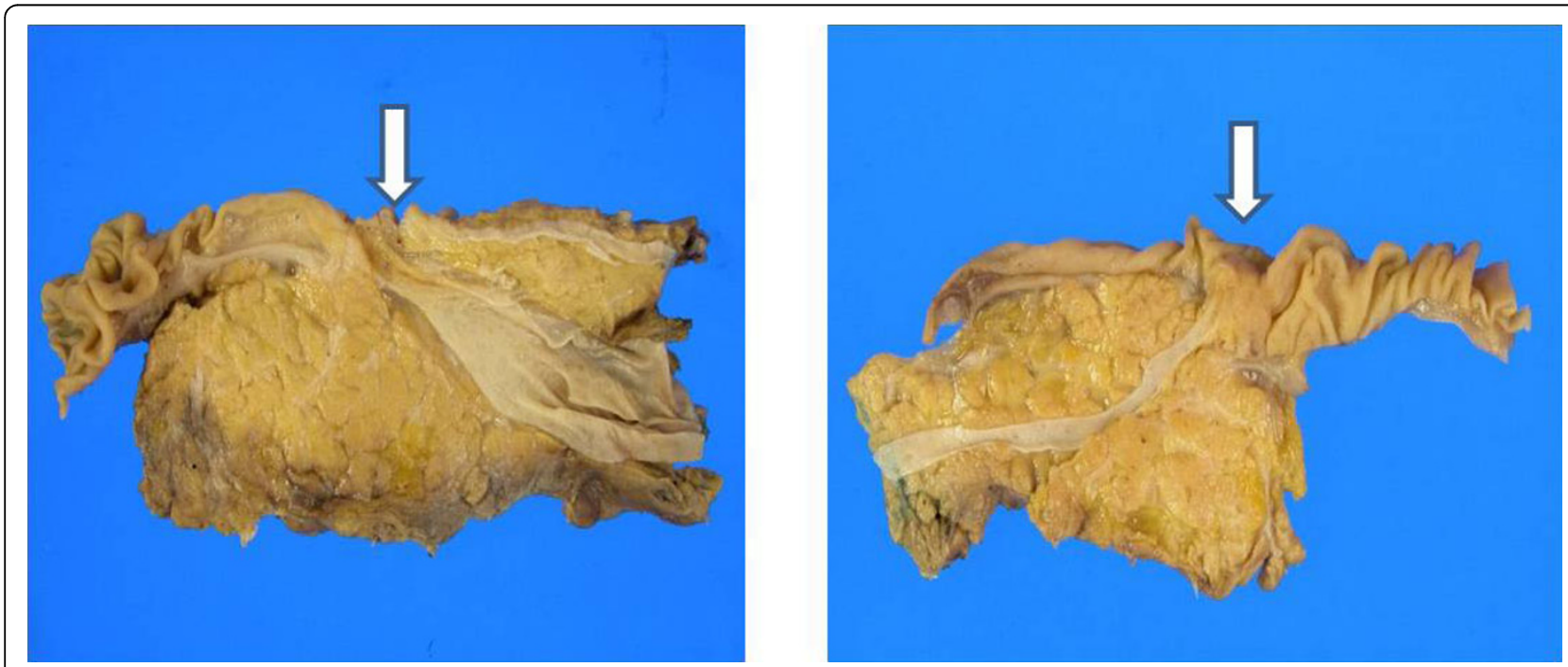

Figure 5 Gross findings of resected specimen. The resected specimen was composed of duodenum, pancreatic head with a part of pancreatic body and common bile duct. There was $1.2 \times 1.0 \mathrm{~cm}$ sized submucosal lesion at minor papilla (arrow). There was no communication between common bile duct (CBD) and pancreatic duct (PD). Furthermore, dorsal pancreatic duct only connected with duct of Santorini and without any branch to major papilla. These findings were appropriate to pancreas divisum. 


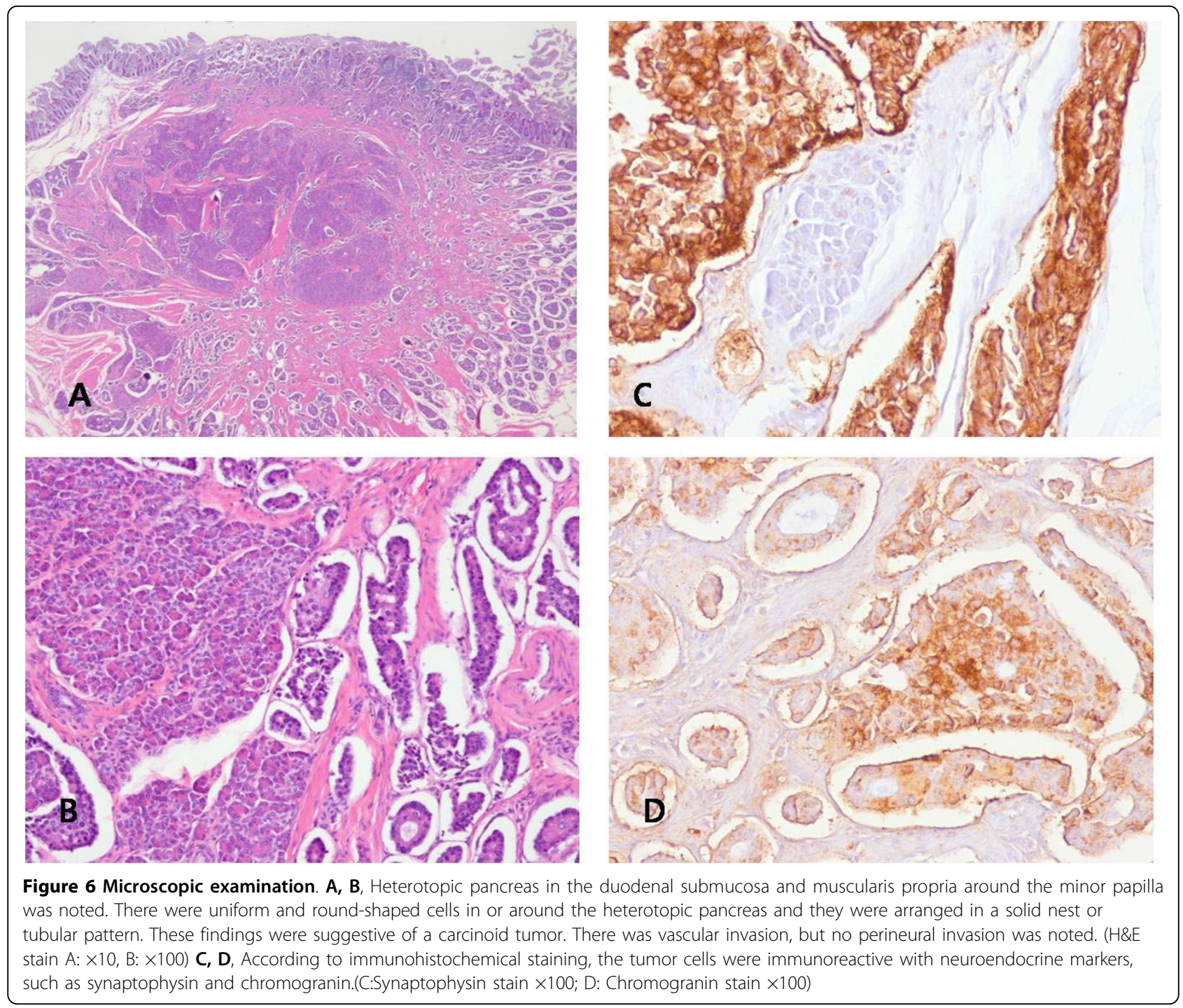

There was vascular invasion, but no perineural invasion was noted (Figures 6A, B). Among the four resected regional lymph nodes, 2 metastatic nodes were detected. The tumor cells showed immunoreactivity to neuroendocrine markers, such as synaptophysin and chromogranin (Figures 6C, D) The patient has been without abdominal pain for 1 year after surgery.

\section{Discussion}

The term carcinoid has been replaced with NET based on the development of diagnostic tools and immunochemistry. Recently, NETs have been reclassified within the spectrum of gastroenteropancreatic-neuroendocrine tumours (GEP-NETs) [9]. However, the term "classical carcinoid" is used synonymously with the term serotonin-producing GEP-NETs [10]. A classical carcinoid tumor is usually still referred to as a carcinoid tumor.
The incidence of gastrointestinal carcinoids is 1.6-2.0 cases per 100, 000 persons per year [11], but the true prevalence may be higher [12]

Although more than 70 cases involving carcinoid tumors of the major papilla have been reported [13], only 8 cases of carcinoid tumors involving the minor papilla have been reported [1-8]. Carcinoids and endocrine cell micronests (ECMs) in the minor papilla occur more frequently than generally thought. In a single surgical specimens and autopsy study, the incidence of carcinoids and neoplastic ECMs of the minor papilla could reach $10 \%$. Furthermore, carcinoids in the minor papilla are twice as common as carcinoids of the major papilla, and neoplastic ECMs of the minor papilla are found five times as often [14]. This discrepancy may be explained by the fact that tumors of the major papilla are more likely to develop symptoms, such as jaundice or 
abdominal pain, due to ampullary obstruction, whereas patients with minor papillary tumors usually remain asymptomatic because there is no biliary or pancreatic obstruction.

Carcinoid tumors of the minor papilla of the duodenum are very difficult to diagnose because they are usually small in size and located at the submucosal area, and they are frequently asymptomatic [15] and rarely accompanied with endocrine manifestations [13]. In our case, although the size of the carcinoid tumor was small and the tumor was hormonally inactive, the concomitant pancreas divisum led to an early diagnosis because obstruction of the minor papilla due to the carcinoid tumor caused recurrent abdominal pain and resulted in dilatation of the main pancreatic duct. Of the eight reported cases of carcinoid tumors involving the minor papilla in the literature, five cases have been associated with pancreas divisum and presented with recurrent abdominal pain or pancreatitis [3-7]

The endoscopic features of carcinoid tumors are small, round, sessile, or polypoid lesions with a smooth surface. Carcinoid tumors usually have normal overlying mucosa and seldom ulcerate [16]. An EUS may be useful for the diagnosis of carcinoids and evaluation of regional lymph node metastasis, but CT or MRI scans are not helpful in most cases because of the small size. Carcinoid tumors usually appear as a homogenous, welldemarcated, and mildly hypoechoic or isoechoic mass that arises from the second layer on EUS. In addition, EUS can define the size, tumor invasion, and regional lymph node metastasis [16]. The pre-operative diagnosis of carcinoid tumors of the duodenal papillae is largely dependent upon endoscopic biopsy. However, a correct diagnosis is made in only $14 \%$ of the patients ${ }^{13}$ because the tumors are usually submucosal in location [13]. As in our case, multiple deep biopsies are required to enhance the tissue diagnosis.

Though endoscopic resection may be an alternative to surgical resection $[8,17]$, radical surgery is usually recommended as the treatment of ampullary carcinoid tumors $[13,18]$ because carcinoid tumors of this area appear to have more aggressive biology with presence of metastasis in approximately $50 \%$ of the cases, irrespective of the size of the primary tumor or mitotic activity $[13,19,20]$. In our case, despite the tumor being $1 \mathrm{~cm}$ in diameter, the histologic examination revealed duodenal and vascular invasion and metastasis to the regional lymph nodes. In conclusion, carcinoid tumors of the minor papilla are very rarely found, but the true incidence might be much higher, and the tumors frequently have aggressive behavior. Carcinoid tumors of the minor papilla should be included in the differential diagnosis of recurrent abdominal pain or pancreatitis of unknown cause.

\section{Consent}

Written informed consent was obtained from the patient for publication of this case report and accompanying images. A copy of the written consent is available for review by the Editor-in-Chief of this journal.

\section{Authors' contributions}

All authors read and approved this manuscript. YGK analyzed and interpreted the patient's data. KOK collected the patient's data. TNK supervised this case report and followed up the patient.

\section{Competing interests}

The authors declare that they have no competing interests.

Received: 15 November 2009

Accepted: 12 February 2010 Published: 12 February 2010

\section{References}

1. Malone MJ, Silverman ML, Braasch JW, Jin GL, Dayal Y: Early somatostatinoma of the papilla of the duct of Santorini. Arch Surg 1985, 120:1381-1383.

2. Wang HY, Chen MJ, Yang TL, Chang MC, Chan YJ: Carcinoid tumor of the duodenum and accessory papilla associated with polycythemia vera. World J Gastroenterol 2005, 11:3794-3796.

3. Stommer PE, Stolte M, Seifert E: Somatostatinoma of Vater's papilla and of the minor papilla. Cancer 1987, 60:232-235.

4. Lowes JR, Rode J, Lees WR, Russell RC, Cotton PB: Obstructive pancreatitis: unusual causes of chronic pancreatitis. Br J Surg 1988, 75:1129-1133.

5. Singh W, Bhutani MS, Draganov P: Carcinoid of the minor papilla in incomplete pancreas divisum presenting as acute relapsing pancreatitis. Pancreas 2003, 27:96-97.

6. Waisberg J, de Matos LL, Waisberg DR, dos Santos HV, Fernezlian SM, Capelozzi VL: Carcinoid of the minor duodenal papilla associated with pancreas divisum: Case report and review of the literature. Clinics 2006, 61:365-368.

7. Outtas O, Barthet M, De Troyer J, Franck F, Garcia S: [Pancreatic panniculitis with intraductal carcinoid tumor of the pancreas divisum]. Ann Dermatol Venereol 2004, 131:466-469.

8. Itoi T, Sofuni A, Itokawa F, Tsuchiya T, Kurihara T, Moriyasu F: Endoscopic resection of carcinoid of the minor duodenal papilla. World J Gastroenterol 2007, 13:3763-3764.

9. Oberg K, Astrup L, Eriksson B, Falkmer SE, Falkmer UG, Gustafsen J, Haglund C, Knigge U, Vatn MH, Valimaki M: Guidelines for the management of gastroenteropancreatic neuroendocrine tumours (including bronchopulmonary and thymic neoplasms). Part I-general overview. Acta Oncol 2004, 43:617-625.

10. Solcia E, Klöppel G, Sobin LH, Williams ED: Histological typing of endocrine tumours. Springer Berlin 2000.

11. Godwin JD: Carcinoid tumors. An analysis of 2,837 cases. Cancer , 2 1975, 36:560-569.

12. Kulke MH, Mayer RJ: Carcinoid tumors. N Engl J Med 1999, 340:858-868.

13. Hatzitheoklitos E, Buchler MW, Friess H, Poch B, Ebert M, Mohr W, Imaizumi T, Beger HG: Carcinoid of the ampulla of Vater. Clinical characteristics and morphologic features. Cancer 1994, 73:1580-1588.

14. Noda Y, Watanabe H, Iwafuchi M, Furuta K, Ishihara N, Satoh M, Ajioka Y: Carcinoids and endocrine cell micronests of the minor and major duodenal papillae. Their incidence and characteristics. Cancer 1992, 70:1825-1833.

15. Machado MC, Bacchella T, Jukemura J, da Cunha JE, Claudia M, Zerbini N, Machado MA, el Hayek OR, Pinotti HW: [Carcinoid tumor of the duodenal papilla]. Rev Hosp Clin Fac Med Sao Paulo 1991, 46:87-90.

16. Hawes RH, Fockens P: Endosonography. [Philadelphia]: Saunders Elsevier 2006, xi:329

17. Cheng CL, Sherman S, Fogel EL, McHenry L, Watkins JL, Fukushima T, Howard TJ, Lazzell-Pannell L, Lehman GA: Endoscopic snare papillectomy for tumors of the duodenal papillae. Gastrointest Endosc 2004, 60:757-764.

18. Modlin IM, Lye KD, Kidd M: A 5-decade analysis of 13,715 carcinoid tumors. Cancer 2003, 97:934-959. 
19. Clements WM, Martin SP, Stemmerman G, Lowy AM: Ampullary carcinoid tumors: rationale for an aggressive surgical approach. $J$ Gastrointest Surg 2003, 7:773-776.

20. Makhlouf HR, Burke AP, Sobin LH: Carcinoid tumors of the ampulla of

Vater: a comparison with duodenal carcinoid tumors. Cancer 1999,

85:1241-1249.

\section{Pre-publication history}

The pre-publication history for this paper can be accessed here:http://www. biomedcentral.com/1471-230X/10/17/prepub

doi:10.1186/1471-230X-10-17

Cite this article as: Kim et al: Carcinoid tumor of the minor papilla in complete pancreas divisum presenting as recurrent abdominal pain. BMC Gastroenterology 2010 10:17.

Submit your next manuscript to BioMed Central and take full advantage of:

- Convenient online submission

- Thorough peer review

- No space constraints or color figure charges

- Immediate publication on acceptance

- Inclusion in PubMed, CAS, Scopus and Google Scholar

- Research which is freely available for redistribution

Submit your manuscript at www.biomedcentral.com/submit 